\title{
WEED-KILLING FERTILISER MIXTURES
}

\author{
F. B. MULLER, New Zealand Fertiliser Manufacturers' \\ Research Association, Auckland.
}

\section{Introduction:}

The incorporation of salts of 2,4-D with fertiliser mixtures offers a simple method of controlling susceptible weeds in pastures while carrying out normal topdressing operations, especially in districts where fertilstser applications are made in the spring. The cost of such weedkilling fertilisers would be only slightly more than the cost of the fertiliser plus the 2,4-D; namely, the cost of mixing. This means that unless a farmer owns a spray outfit or has access to one, the hormonised fertilisers would be the cheapest way of treating weed-infested pastures.

Work done in the United States on the use of mixed fertilisers as carriers for 2,4-D in controlling weeds in lawns has shown that $1 \frac{1}{2}$ to 31 b. of 2,4-D mixed with 600lb. of mixed fertiliser and applied at that rate per acre killed many lawn weeds and increased the grass crop as a result of a significant reduction in weed competition and the nourishing action of the fertiliser (3).

Further work done with these mixtures, some of which had been subjected to temperatures of up to 60 degrees C. for 2 weeks at the beginning of the storage period to simulate the curing conditions of mixed fertilisers, showed that equally satisfactory results were obtained in weed control after the mixtures had been stored for 10 months.

The first commercial mixtures containing 2,4-D and fertilisers appeared on the United States market in 1947 (4). By 195010 different brands were registered, containing from 0.5 per cent. to 1 per cent. 2,4-D.

The hormone weedkillers applied as sprays are generally more efficient per unit of active material than when they are applied as dusts (2). However, the benefits derived from mixing the hormone with fertiliser materials would in many cases outweigh this loss of activity.

Experiments were undertaken at the Fertiliser Manufacturers' Research Association in Auckland with hormone-fertiliser mixtures in order to find out whether effective control of pasture weeds could be obtained under local conditions and using the standard phosphate fertilisers as carriers.

\section{Experimental Work}

The experimental works falls into 3 sections following upon the method of adding the hormone to the fertiliser:

A. Dry-mix formulations in which the hormone is added as a powder to the fertiliser.

B. Wet-mix formulations in which the hormone is added to the fertiliser at some stage in the manufacture of the latter.

In this paper, "wet-mix" will refer to the addition of 2,4-D either to the sulphuric acid before mixing with the ground phosphate rock; or the addition of the 2,4-D to the sulphuric acid-phosphate rock slurry before pouring into the den.

As it is very difficult to simulate in laboratory preparations the conditions which would apply in commercial practice, 2 separate lots of experimental wet-mix formulations were prepared; small scale laboratory mixes and large scale (i.e. commercial scale) mixes. 
C. Damp-mix formulations in which a stabilised water suspension of the hormone is sprayed on and mixed with the fertiliser.

In each case the resultant experimental products were tested for effectiveness in weed control in small plot trials and where possible in field scale trials. Chemical extractions of the hormone from the various formulations were also undertaken to determine the percentage of recoverable hormone, which provided a further check on the mixtures.

\section{A. Dry-mixing of 2,4-D With Superphosphate}

\section{PLOT TRIALS}

Trials were initiated in October, 1950, to compare 2,4-D applied as a water spray (using the sodium salt) with dry-mix formulations. The following treatments were applied to replicated and randomized 0.01 acre plots:

\section{Table 1. Per Cent. Weed Control From Dry-mix Materials}

Treatment

2cwt. superphosphate + 0.75lb. 2,4-D per acre

2cwt. serpentine super $+0.751 \mathrm{~b}$. 2,4-D per acre $\ldots$

3cwt. limestone $\quad+0,751 \mathrm{~b}, 2,4-\mathrm{D}$ per acre.

Spray (50 gallons water) $+0.751 b$. 2,4-D per acre .
Per Cent.

Weed Control
89
84
97

Estimates of weeds were made 4 weeks after the materials were applied. The main weeds present in this trial, and in subsequent experiments were buttercups (Ranunculus spp.), docks (Rumex spp.), mallows (Malva spp.), daisies (Bellis perennis), catsear (Hypochaeris radicata), and Scotch thistles (Cirsium lanceolatum).

Half the plots were treated with freshly mixed materials and the rest with materials mixed 6 weeks before application. There was no loss of effectiveness due to the 6 weeks' storage period.

\section{Table 1A. Per Cent. Weed Control in Storage Trial}

\section{Treatment}

Average Per Cent. Weed Control

Freshly mixed

Stored for 6 weeks

As a whole, the hormonised fertiliser materials gave slightly poorer weed control than the spray which gave practically complete control Five months after treatment the plots were still free from weeds while the controls were heavily infested.

It is not known why the limestone mix was lower in effectiveness than the other materials. Perhaps the slight acidity of the carrier may have an effect upon the herbicidal properties of the hormone.

\section{FIELD TRIALS}

In November, 1950, field trials were made to see how the hormonised materials would work under normal field conditions, using ordinary farm equipment.

The trial was laid out on replicated $\frac{1}{4}$ acre plots, measuring $\frac{1}{2}$ chain by 5 chains. Three rates of 2,4-D were applied with 2cwt. of super phosphate per acre; 0.37lb., 0.75lb. and $1.12 \mathrm{lb}$. acid equivalent, compared with 0.751 . 2,4-D as a water spray.

With the fertiliser mixes a slightly better kill of weeds was obtained with hormonised superphosphate containing $1.121 \mathrm{~b}$. than with the $0.751 \mathrm{~b}$. 
2,4-D mixtures. The spray at $0.751 \mathrm{~b}$. per acre was slightly better than with the $0.75 \mathrm{lb}$. dry application and about the same as the 1.12lb. application. The lowest rate, $0.371 \mathrm{lb}$, did not give satisfactory control, even with such susceptible weeds as buttercups and plantain.

In all experiments $11 \mathrm{~b}$. of sodium salt of 2,4-D was used. This formulation contains $\frac{3}{4} \mathrm{lb}$. of 2,4-D acid.

Throughout this paper all amounts of 2,4-D are given as the acid equivalent. To convert quantities of 2,4-D acid to the equivalent as the sodium salt of $2,4-\mathrm{D}$ add one-third.

Before the experiment the topdresser was calibrated, and a known excess of material was put in the machine and after each treatment the remainder was weighed. By doing this, it was found that the amount actually applied (and it was a very efficient topdresser) could vary as much as 15 per cent. of the desired amount. Condition of the fertiliser, roughness of the ground, weather conditions, blockage of one or more outlets could increase or decrease the amount of material actually applied.

The 1.12lb. rate clearly showed the uneven spread of the fertiliser. In the rougher area of the paddock the sward had a "washboard" effect, caused by uneven distribution of the material. This caused slight scorching of the grass and could be clearly seen some distance away, as alternating green and yellow bands. This heavier 2,4-D application affected the clover to a slight extent, but it recovered after a few weeks.

During the application of the materials the work was interrupted several times by rain squalls. It was thought that a decrease in weed control would result because of loss of material from the leaves. As it happened, excellent control was obtained. The rain, which did not run off the leaves to any extent, may have had a beneficial effect by causing the dust to adhere to the foliage, thus allowing maximum penetration of the hormone.

It was concluded that, in order to compensate for the slightly lower effectiveness of dry mixtures as compared with the spray application of 2,4-D, the unevenness of topdresser application, and the inability to supply exactly the required amount of fertiliser, not less than $\frac{3}{4} \mathrm{lb}$. of 2,4-D per acre should be applied with fertiliser carriers.

\section{B. Wet-mixing of 2,4-D During Superphosphate Manufacture}

As a possible demand for ready-mixed hormonised fertilisers was expected to develop, work on the commercial production of such materials was undertaken. To reduce handling of materials and to cut down the dust hazard the first approach to the problem of making hormonefertiliser mixture was that of adding the 2,4-D to the fertiliser during its manufacture.

There are two ways of doing this: 1. Adding the hormone to the sulphuric acid before it is added to the rock. 2. Adding the 2,4-D to the sulphuric acid befid-rock slurry.

Experimental mixtures were made at the Fertiliser Manufacturers' Research Laboratories using both methods of incorporating the hormone with the super compound. In the case of the acid mixes, the 2,4-D was allowed to remain for varying periods of time before pouring the acid into the rock. In addition, several experimental products commercially made by adding the hormone to the slurry were obtained and all of the mixtures were tested for effectiveness in plot trials and by chemical analysis. 


\section{SMALL PLOT TRIALS}

All carriers were applied at the rate of 2cwt. per acre, except for the spray where 50 gallons of water was used. The plots were treated in April, 1951, and the weeds estimated in June. This was too late in the season for optimum weed control, though satisfactory comparative results were obtained.

The following materials were used in the small plot trials:

Table 2. Per Cent. Weed Control From Wet-mix Materials

Materials

Amt. 2,4-D Per Cent.

per acre Weed Control

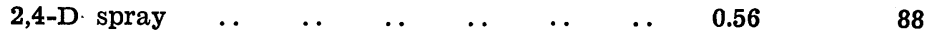

2,4-D to acid-mixed immediately to rock $\quad \ldots \quad 1.12 \quad 82$

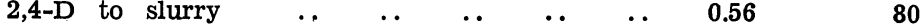

2,4-D to acid-mixed immediately to rock $\ldots \quad 0.56 \quad 77$

Dry-mixing; 2,4-D to cured super $\quad . \quad \ldots \quad \ldots \quad 0.56 \quad 72$

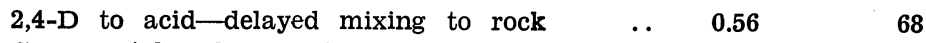

Commercial-scale experimental slurry mix $\quad \ldots \quad 1.12 \quad 66$

Commercial-scale experimental slurry mix $\quad \ldots \quad 0.56 \quad 44$

The F.M.R.A. experimental compounds gave good results when the 2,4-D was added to the acid-rock slurry or to the acid and mixed with the rock immediately. The experimental commercial slurry mixes showed up as being less satisfactory. On a small scale basis the "wet-mix" method appears to work, but when it is done on a commercial scale the 2,4-D shows a one-third decrease in effectiveness for killing weeds.

Further small field trials showed that the commercial mix to $11.2 \mathrm{lb}$ 2,4-D per ton of super compound was about equal in weed-killing power to dry mixes at 7.5lb. 2,4-D per ton of fertiliser.

\section{CHEMICAL EXTRACTIONS}

As a check on the amount of 2,4-D available to kill weeds in these various materials, chemical extractions of the 2,4-D were made.

The following table gives the amount of 2,4-D recovered from large scale and small scale experimental mixes:

Table 3. Recovery of 2,4-D From Wet-mix Materials

\section{Material}

2,4-D to cured superphosphate

2,4-D to acid immed. mix (F.M.R.A.)

2,4-D to slurry (F.M.R.A.) .. .

Commercial large-scale slurry mix ..

Commercial large-scale slurry mix
Calc. Amt. Amount Recovery 2,4-D Recovered Per Cent.

$0.333 \mathrm{~g}$

$0.250 \mathrm{~g}$

$0.297 \mathrm{~g}$

$0.198 \mathrm{~g} \quad 80$

$\begin{array}{llll}0.250 \mathrm{~g} & 0.198 \mathrm{~g} & 80\end{array}$

$0.500 \mathrm{~g} \quad 0.302 \mathrm{~g} \quad 60$

$\begin{array}{llll}\ldots & 0.250 \mathrm{~g} & 0.148 \mathrm{~g} & 58\end{array}$

The chemical extractions are in close agreement with the weed control trials. The small scale "wet-mixes" gave higher recoveries 2,4-D than the large-scale products, but still lower than the dry mix. Again in the large scale mixes only two-thirds of the 2,4-D is easily recoverable as compared with the dry mix.

These chemical extractions can give an indication of the amount of 2,4-D which is available to kill weeds. The rest of the hormone, which cannot be easily recovered, might be called "unavailable" as far as weed control purposes are concerned. 
What happens to the hormone during the various methods of mixing is not known. In dry-mixing, the 2,4-D coats individual particles of fertiliser; and theoretically all the 2,4-D is able to come in contact with the weeds. In "wet-mixing," the hormone becomes part of the super compound, and a considerable amount of the hormone is distributed throughout the fertiliser granules, thereby never coming in contact with the weeds unless the granules dissolve on the leaves.

Also, the temperatures reached in large-scale superphosphate manufacture are much higher and remain high for a longer period of time than when small experimental batches are made up. These high temperatures plus the strong acidity of the mixture may cause partial decomposition of the hormone.

In any case the loss of the weed-killing properties in the "wetmixing" method under large scale operations is so great that this method had to be abandoned in favour of some form of dry mixing.

\section{Addition of 2,4-D as a Water Suspension to Super Compound}

This was done by making a stabilised water suspension of the 2,4-D and adding this to the super compound at some stage before bagging. The slight dampening effect would cut down the dust hazard without affecting the physical properties of the fertiliser. This might be called "damp mixing."

A weed-control trial was put down in January of this year to compare the "damp mixes" with the 2,4-D spray and dry mixes. The season was not entirely favourable for good weed-control because of the dry conditions. However, the damp-mixed products gave results comparable with those cbtained from the dry-mixes and spray application.

The official A.O.A. method (1) for extracting 2,4-D acid from various carriers was used. The method was modified for use with fertiliser mixtures by adding sufficient $\mathrm{NaOH}$ to make the fertiliser solution strongly alkaline before making the ether extraction.

\section{CHEMICAL ANALYSES}

Chemical extractions of 2,4-D from the damp mixes were compared with recoveries made from several other mixtures:

Table 4. Recovery of 2,4 D From Various Materials

Calc.Amt.

\begin{tabular}{|c|c|c|c|c|}
\hline Materials & & 2,4-D & $\begin{array}{c}2,4-D \\
\text { Recovered }\end{array}$ & Per Cent. \\
\hline $\begin{array}{l}\text { Sodium salt 2,4-D } \\
\text { 2,4-D dissolved in } 88 \text { per cent. }{ }^{\text {H2S }}\end{array}$ & & 1.08 & 1.045 & 97 \\
\hline and left for 2 weeks $\ldots$ & & 0.57 & 0.543 & 95 \\
\hline Hormonized limestone & .. & 0.35 & 0.329 & 94 \\
\hline ry-mix (F.M.R.A.) & .. & 0.32 & 0.295 & 92 \\
\hline amp-mixing (large-scale production) & .. & 0.50 & 0.420 & 84 \\
\hline Wet-mixing (large-scale production) & & 0.50 & 0.315 & 63 \\
\hline
\end{tabular}

The amount of 2,4-D recovered from the damp mixes is less than the amount recovered from the dry mixes or the lime mixes but considerablv higher than that from the large-scale wet-mixes. Evidently dissolving the 2,4-D before adding it to the fertiliser increases to a slight extent the absorption of the hormone.

The 95 per cent. recovery of 2,4-D from the stored strong sulpuric acid solution indicates that it is mainly a physical phenomenon which inactivates the hormone rather than chemical decomposition. The dry-mix and hormonised lime had the highest recovery, the damp-mix slightly less, and the wet-mix about two-thirds.

65 
It is interesting to note that the amount of 2,4-D recovered from the dry-mix is very high; 92 per cent. This material was mixed in August. 1950,21 months before these analyses. The large scale wet-mix(addition of 2,4-D to the acid-rock slurry) also showed no decrease in the amount of 2,4-D recovered after over 1 year in storage. After the initial absorption there seems to be no further loss of the hormone.

In other words, the hormonised fertilisers can be carried over from one season to the next without any loss in their weed-killing properties.

\section{CONCLUSIONS}

In using these hormonised materials, there are certain precautions which must be observed if satisfactory control of weeds it to be obtained. The most important are those associated with the weather.

Since 2,4-D is applied dry, and there is considerable coarse material in the carriers, better results will be obtained if the top-dressing is done early in the morning while there is still dew on the foliage. This will allow most of the fine fraction to stick on the leaves, and when dry this coating is somewhat resistant to light rain. Also since there is moisture on the plants more rapid and thorough penetration of the hormone takes place.

Clear weather for 24 hours following the application ensures good results, while light rain following topdressing does not interfere providing the material is not washed off for a day or two. We even had good results by topdressing between light rain squalls.

A further advantage of early morning application is that at this time there is less chance of wind. Calm conditions during application give more even distribution of the materials, better absorption of the hormone, and less danger to nearby crops from wind drift of the fine fraction.

The best time to apply these materials is in the spring (October and November) when the ground is moist and soil temperatures are rising. The weeds are then growing vigorously and are generally in their most susceptible stage. Spring topdressing is a normal practice in most dairying districts so the hormonised fertilisers can be applied without altering farm routine. It may be necessary to make a special effort to apply the hormonised fertiliser at a certain time because of weather conditions, but this would apply to a few paddocks only.

Our work has shown that the sodium salt of 2,4-D when applied as hormonised super compound is effective for the control of susceptible weeds. However, except for ideal conditions of application this mixture is slightly less effective than equal quantities of 2,4-D per acre applied as a spray.

For this reason and because of uneven topdresser distribution at least $\frac{3}{4}$ of a pound of 2,4-D acid equivalent should be applied per acre in fertiliser mixtures. Ono lb. may even be preferable should weather conditions be unfavourable for a good weed control.

The value to the farmer of these hormonised materials will depend upon several factors. Generally sheep will control most weeds susceptible to the amount of 2,4-D applied in these mixtures. Therefore these compounds will mostly find application on dairy farms.

The degree of infestation is also another factor. If the area is uniformly infested with susceptible weeds, then it is worth the cost to topdress with the hormone fertiliser. On the other hand, if there are only patches of weeds, considerable loss is involved by treating areas which do not need it. 
For the farmer who has not a spray outfit or who has not access to one, these hormonised compounds offer the most convenient method of reducing the weed population on his farm. Any area where the topdresser can go can be treated. The cost of the materials is only a few shillings per acre more than the cost of the 2,4-D and super compound alone. Even with this extra cost and the slightly lower effectiveness of the hormone in this form, it would more than make up for the extra time and expenditure involved in going over the same area twice.

These weed-killing mixtures are available in the North Island for the coming season.

"Hormonised lime" contains 1.81b. 2,4-D per ton of limestone. The material is to be applied at the rate of 10cwt. per acre, thereby applying 0.9lb. of 2,4-D per acre.

Hormonised super compound is being marketed at two rates: 5.6 and 11.2lb. 2,4-D per ton of super compound. The recommended rates would be, for a 3 to 4cwt. per acre application, to use the weaker mixture which would give $0.84-1.12 \mathrm{lb}$. of $2,4-\mathrm{D}$ per acre. The stronger mixture, applied at $1 \frac{1}{2}$ to 2cwt. would give 0.84 to $1.12 \mathrm{lb}$. 2,4-D per acre also.

To summarize, weed-killing fertiliser mixtures are effective in controlling susceptible pasture weeds as well as performing their main purpose of supplying nutrients. Certain precautions must be observed regarding time of application and weather conditions during and following the topdressing.

For best results between $\frac{3}{4}$ of a pound and 1 pound of 2,4-D per acre should be applied because of the slightly lower effectiveness of the 2,4-D applied in this way and because of the unevenness of topdresser applications.

When these precautions are taken good results can be obtained at relatively low cost per acre by the use of hormonised fertilisers.

\section{LITERATURE CITED}

(1) Association of Official Agricultural Chemists, Official Methods of Analysis. Herbidices $5.129(\mathrm{~b})$. Washington, 1950.

(2) Lynch, P. B., Chemical methods of weed control. N.Z. Dept. of Agric Bulletin No. 329.

(3) Marth, P. C., Hardesty, J. O., and Mitchel, J. W. Stability of 2,4-D when stored with mixed fertiliser. Agric. Chemicals 4: 41, No. 5, May, 1949.

(4) Mehring, A., 7, Combination fertilisers and pesticides. Commercial Fertiliser, January, 1951.

Acknowledgments are made to the N.Z. Farmers' Fertiliser Company for supplying experimental hormone fertiliser mixtures; and to the Imperial Chemical Industries (Auckland) for supplying the 2,4-D used in these trials.

\section{DISCUSSION}

Q. Has Mr. Muller found any residual effect through using the wet $\mathrm{mix}$ ?

A. I have not noticed any.

Q. With granulated as compared with powder mixes there is a possibility of separation of the active hormone fraction from the fertiliser fraction, especially with spinner type spreaders. Have you used any
granulated form of mixture?

A. No. 
Q. I am interested in the possibilities of hormones and mixtures for air distribution.

A. All the work has been done with normal topdressers on flat land and mostly on dairy farms.

Q. What is the result of wet mix on docks?

A. Docks are one of the weeds over which there is fairly good control. With trials in October, fairly large leafy dock plants-not yet gone to seed-were not killed but considerably damaged.

Q. Did crowns come back the same year?

A. No. As material was put on, docks faded away and no more came back that year.

Q. Have the Manufacturers' Association paid attention to question of return of bags, including paper bags? I have heard of bags being emptied and the sweepings sold to farmers.

A. That would be disastrous in some circumstances. To overcome this manufacturers have their bags marked with "Hormone Fertilizer" right across them so that bags cannot be re-used.

Q. What are the relative prices of spraying and dusting with powder?

A. I don't know what the cost of spraying would be. Mixture A contains $5 \frac{1}{2} l$ b. 2,4-D acid per ton and a 3cwt. dressing would cost £2 an acre. Mixture B contains 11lb. 2,4-D acid per ton and a 2cwt. dressing would cost $£ 1 / 13 /-$ per acre.

Q. Do you cater for Taranaki farmers who may use up to 8cwt. super per acre?

A. The Taranaki farmer would not be able to use the mixtures under these circumstances. 